\title{
Associations between dietary patterns and serum lipids, apo and C-reactive protein in an adult population: evidence from a multi-city cohort in South America
}

\author{
Rosana Poggio $^{1 *}$, Natalia Elorriaga ${ }^{1}$, Laura Gutierrez ${ }^{1}$, Vilma Irazola ${ }^{1}$, Adolfo Rubinstein ${ }^{1}$ and \\ Goodarz Danaei ${ }^{2}$ \\ ${ }^{1}$ Southern Cone American Center of Excellence for Cardiovascular Health, Institute for Clinical Effectiveness and \\ Health Policy (IECS), Buenos Aires C1414CPV, Argentina \\ ${ }^{2}$ Harvard T.H. Chan School of Public Health, Boston, MA 02115, USA
}

(Submitted 18 November 2016 - Final revision received 1 February 2017 - Accepted 10 February 2017)

\section{Abstract}

Several previous epidemiological studies from developed countries have shown that an unhealthy dietary pattern affects plasma lipid levels and inflammation biomarkers. We assessed the cross-sectional associations between dietary patterns and cardiovascular risk factors among 961 adults from a multi-city cohort in South America. We conducted a principal component analysis to derive dietary patterns. As outcomes, we examined plasma levels of apo A-I, apo B, high-sensitivity C-reactive protein (hs-CRP), LDL-, HDL- and serum total cholesterol and TAG. The crude and adjusted changes in each outcome were estimated for quartiles of dietary patterns using multivariable linear regression models. The prudent pattern (PP) characterised by higher intake of fruits, vegetables, fish, seafood, whole cereal and low-fat dairy products was associated with reduced plasma concentrations of apo B $(-8.5 \mathrm{mg} / \mathrm{l})$, total cholesterol $(-18.8 \mathrm{mg} / \mathrm{dl})$ and LDL-cholesterol $(-16.5 \mathrm{mg} / \mathrm{dl})$ and hs-CRP $(-1.6 \mathrm{mg} / \mathrm{l})$ in men. In women also reduced plasma concentrations of apo B $(-6.6 \mathrm{mg} / \mathrm{l})$, total $(-12.0 \mathrm{mg} / \mathrm{dl}) \mathrm{and} \mathrm{LDL}(-9.3 \mathrm{mg} / \mathrm{dl})$. The $" \mathrm{Western}-$ like' pattern characterised by higher intake of eggs, pastry and cakes, pizza, snacks, refined grains, red meat, vegetable oils and poultry was not significantly associated with any of the selected serum lipid or inflammatory biomarkers. The explained variances were $10 \cdot 3$ and $7 \cdot 4 \%$, respectively. The PP was associated with better lipid profile, mainly lower atherogenic particles (apo B) and LDL-cholesterol and serum total cholesterol. This study provides possible evidence of a prudent diet in South American populations to help reduce the burden of CVD

\section{Key words: Dietary patterns: Apolipoproteins: Principal component analysis: C-reactive protein}

Unhealthy diet is the most important cause of burden of disease globally ${ }^{(1)}$ and in many developing regions ${ }^{(2)}$. In South America, unhealthy diet caused $10.5 \%$ of total burden of disease (1 670656 disability-adjusted life years (DALY)), $72 \%$ of the burden from CHD (1214996 DALY) and 23\% of the burden from diabetes (252 259 DALY) in $2015^{(3)}$. The global prevalence of diabetes reported by The Study of Detection and Follow-up of Cardiovascular Disease and Risk Factors in the Southern Cone of Latin America (CESCAS I) was 12.4\% and the selfreported prevalence of $\mathrm{CHD}$ was $6.9 \%{ }^{(4)}$.

The impact of unhealthy diet on chronic disease in this region is expected to increase - as trends in diet show increasing total energy intake, particularly from sugars and fats ${ }^{(5)}$ and lower consumption of fruits and vegetables than recommended ${ }^{(6)}$. In last decade, there was a significant increase in the availability of energy content in Latin America and this pattern was observed in seventeen of the twenty countries analysed. Countries in South America tended to have a greater increment than those in the Andean region, Central America or the Caribbean. In Argentina, the available energy (daily energy per capita) increased from 2090 in 1990 to $3070 \mathrm{kcal}(12845 \mathrm{~kJ})$ in 1999, in Chile from $2610 \mathrm{kcal}(10920 \mathrm{~kJ})$ to $2850 \mathrm{kcal}(11924 \mathrm{~kJ})$ and in Uruguay from $2600 \mathrm{kcal}(10878 \mathrm{~kJ})$ to $2910 \mathrm{kcal}(12175 \mathrm{~kJ})^{(7,8)}$. Total fat and SFA intake has also dramatically increased in South America from $25 \%$ in 1964 to $30 \%$ in 1996. Sugar intake also increased from $15.9 \%$ in 1970 to $16.9 \%$ of energy in $1997^{(9)}$.

Traditional nutrient studies often evaluate single nutrients or food items and are therefore unable to examine the impact of interactions between different nutrients or foods ${ }^{(10)}$. In contrast, dietary patterns allow assessment of the relationship between overall diet and disease, and often provide associations that are stronger and more consistent than those found by analysing single nutrients or foods ${ }^{(11,12)}$.

Several previous epidemiological studies from developed countries have shown that an unhealthy dietary pattern affects

Abbreviation: hs-CRP, high-sensitivity C-reactive protein.

* Corresponding author: R. Poggio, fax: +54 114777 8767, email rpoggio@iecs.org.ar 
plasma lipid levels, inflammation biomarkers and other cardiovascular risk factors ${ }^{(13,14)}$. As there is no published data describing the impact of diet on biological risk factors in populations of the Southern Cone of Latin America, our aim was to identify the major dietary patterns in four cities in Argentina, Chile and Uruguay and examine whether those dietary patterns are associated with plasma levels of apo A-I, apo B, C-reactive protein, cholesterol and TAG.

\section{Methods}

\section{Study population}

The CESCAS I study is an observational prospective cohort study with a representative sample of 7524 participants aged 35-74 years from four mid-sized cities (50 000-240 000 inhabitants) representing the Southern Cone of Latin America: Bariloche and Marcos Paz in Argentina, Temuco in Chile and Pando-Barros Blancos in Uruguay.

The sampling design included four stages to obtain a representative sample from the general population in each city. The eligibility criteria were: being a permanent resident at the location for at least 6 months per year, willing to sign a consent form to participate, not intending to relocate within the next 2 years and able to respond autonomously to the questionnaire (i.e. not having cognitive impairment or language problems). We did not replace participants if they refused to participate or were not located. More details of the study are published elsewhere $^{(15)}$.

For this analysis, we excluded 182 participants without baseline information on date of birth, body weight, height, smoking status, diabetes, educational level or physical activity; 173 who did not provide a blood sample; 307 that were receiving lipidlowering drugs; and 368 who had a history of cancer or CVD. In addition, we excluded 1466 participants who did not provide information on diet or had more than seventy items blank on the FFQ or reported a total daily energy intake outside the range of 600-4000 kcal (2510-16740 kJ) (Fig. 1). After all these exclusions, we considered 5028 participants eligible for this analysis. Out of this eligible subset, 961 participants ( 312 from Chile, 310 from Uruguay and 339 from Argentina) were randomly selected to determine apo A-I, apo B and high-sensitivity C-reactive protein (hs-CRP) from the frozen serum samples collected at baseline. All participants provided an informed consent and the study was approved by the Institutional Review Boards in Argentina, Chile and Uruguay.

\section{Data collection}

Baseline data were collected in two stages: (1) in homes and (2) in health centres. Information on medical history, socio-demographic characteristics and alcohol consumption was collected in participants' homes using the same validated questionnaires used in the Hispanic Community Health Study/Study of Latinos $^{(16)}$. Smoking status was assessed using a locally-validated version of the Global Adult Tobacco Survey ${ }^{(17)}$ and physical activity using the International Physical Activity Questionnaire ${ }^{(18)}$. In health centres, anthropometric measurements were carried out, blood pressure was measured and a fasting blood sample was collected. Participants were asked to fast for at least $12 \mathrm{~h}$ before the blood withdrawal. Plasma samples were processed and temporarily stored at $-20^{\circ} \mathrm{C}$ for a maximum of a week at the extraction site, then sent to the central laboratory in Hospital Italiano of Buenos Aires and stored in a blood sample repository at $-80^{\circ} \mathrm{C}$. Diet was assessed using a previously validated 126-item

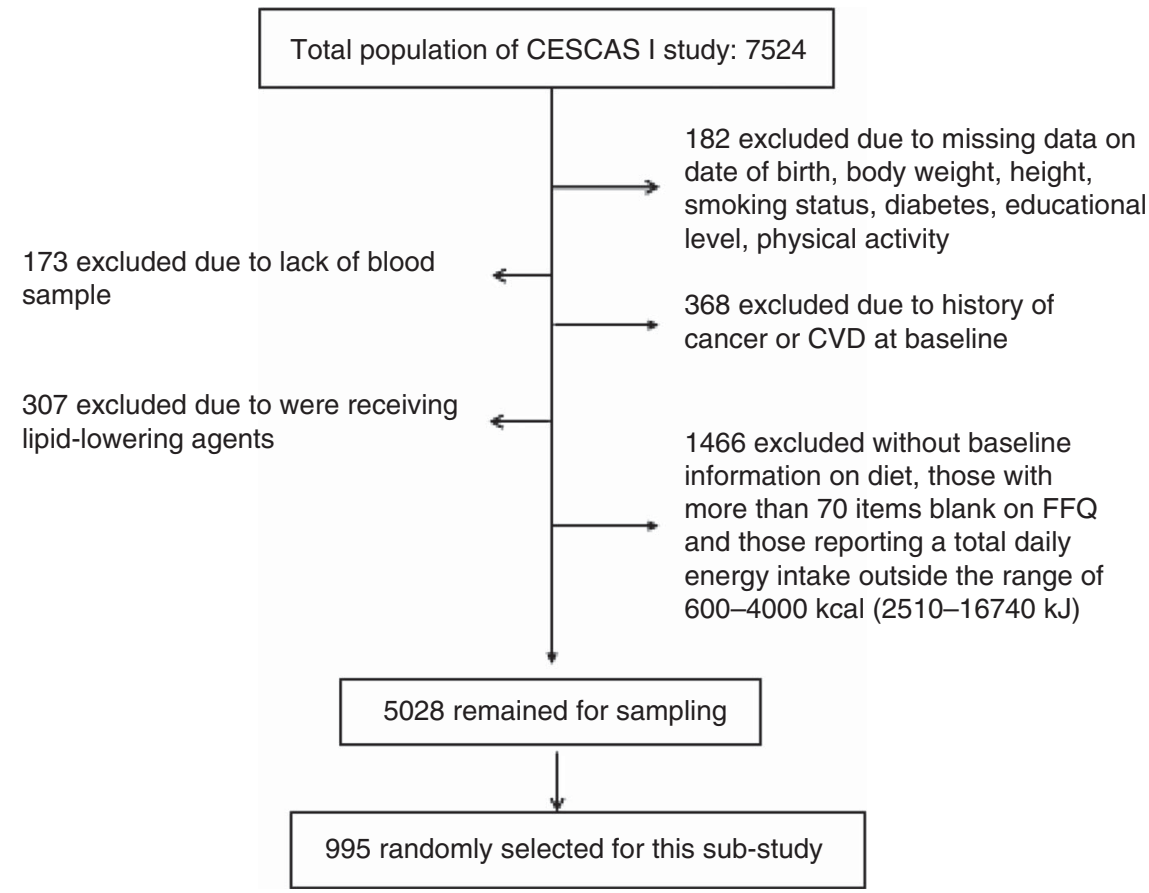

Fig. 1. Flow chart for selection of participants (The Study of Detection and Follow-up of Cardiovascular Disease and Risk Factors in the Southern Cone of Latin America (CESCAS I) study) 
$\mathrm{FFQ}^{(19)}$. Nutrient intakes were estimated by summing the nutrients of all food items using the Argenfoods ${ }^{(20)}$ and Latinfood Databases $^{(21,22)}$. For fatty acid types (SFA, MUFA and PUFA), we used data from the 21st release of the US Department of Agriculture's National Nutrient Database for Standard Reference $^{(23)}$. Apo were measured using kinetic immunonephelometry (IMMAGE ${ }^{\circledR}$ Immunochemistry System). The reagents materials are those accepted for the WHO/IFCC International Reference Reagent ${ }^{(24)}$. Total cholesterol, HDL, TAG and glucose plasma concentrations were processed by Synchron LX System. The LDL levels was calculated using the Friedewald equation for the participants who had TAG $<400 \mathrm{mg} / \mathrm{dl}$. hs-CRP was measured by a sensitive latex turbidimetric immunoassay method.

\section{Statistical analyses}

Food items were collapsed into thirty-five predefined groups to minimise within-person variation in consumption of individual foods. Food groups were defined based on food groups used in other studies ${ }^{(25-28)}$ and collapsing food items according to their habitual culinary use or nutrient composition. Some items (e.g. coffee, tea and mate, a local brew) were kept separate because they were considered to represent distinctive food choices. This classification, a summary of the available food products, was developed by a nutritionist with experience in nutritional epidemiology in the region.

We conducted a principal component factor analysis to derive major dietary patterns. The number of factors retained was based on the following criteria: components with an eigenvalue $>1$, scree plot test and the interpretability of the factors. The factors identified were rotated by an orthogonal transformation, which maintains uncorrelated factors and achieves a simpler structure with greater interpretability ${ }^{(29)}$. The factor score for each pattern was constructed by summing observed intakes of the component food items weighted by factor loadings.

All analyses were performed separately for women and men and for each dietary pattern. To examine the univariate associations between dietary patterns, general characteristics and CVD risk factors, we used univariate linear regression models for continuous variables and $\chi^{2}$ extended Mantel-Haenszel for linear trend for categorical variables. Multivariable linear regression models were used to examine the associations between dietary pattern scores and apo A-I, apo B, hs-CRP, total cholesterol, HDLcholesterol, LDL-cholesterol and TAG. The models included age, education, energy intake, physical activity, diabetes, smoking status and BMI as potential confounders based on results of previous studies ${ }^{(10,30,31)}$. We examined statistical interactions between dietary patterns and BMI (categorical) and age (continuous) by adding product terms to the multivariable models. Total cholesterol, LDL and hs-CRP were log-transformed to reduce the skewness in the distribution of the data.

In a sensitivity analysis, we dropped BMI from the multivariable model because it may be an intermediate factor in the causal pathway between dietary patterns and the selected outcomes. All calculations were weighted to represent the general adult population aged between 35 and 74 years in the study sites. Weights were calculated on the basis of data from the 2010 Population Census and the CESCAS I study sampling scheme, and took into account several features of the survey ${ }^{(15)}$. All tests were two sided. Statistical analyses were performed using STATA version 11.0 (StataCorp LP) and took into account the complex sampling strategy using survey commands ('svy').

\section{Results}

\section{Food consumption patterns}

Two major dietary patterns were identified in this population which together accounted for $18 \%$ of the total variance in food items (Table 1). We labelled the first pattern 'prudent diet' as it was mainly characterised by higher intake of fruits, vegetables, seafood, whole cereal and low-fat dairy products being similar to other prudent patterns described elsewhere ${ }^{(26,32,33)}$, but also showed a smaller load of potatoes and tubers. We called the second pattern 'Western diet' (WL) but it may well represent a combination of the Western pattern described in the United States of America and Canada ${ }^{(26,32,34)}$ with foods like eggs, pastry and cakes, pizza, snacks and refined grains as well as traditional Argentine foods such as red meat, vegetable oils and poultry (Table 1).

Table 1. Food-group rotated loadings for two dietary patterns identified from FFQ data*

\begin{tabular}{|c|c|c|}
\hline Food groups & $\begin{array}{c}\text { Prudent } \\
\text { diet }\end{array}$ & $\begin{array}{c}\text { Western-like } \\
\text { diet }\end{array}$ \\
\hline Other vegetables & 0.78 & \\
\hline Green, leafy vegetables & 0.65 & \\
\hline Fruits & 0.62 & -0.19 \\
\hline Cruciferous vegetables & 0.60 & -0.10 \\
\hline Dark-yellow vegetables & 0.59 & \\
\hline Tomato & 0.52 & \\
\hline Fish and other seafood & 0.44 & 0.13 \\
\hline Potatoes and tubers & 0.39 & 0.36 \\
\hline Whole grains and legumes & 0.27 & \\
\hline Tea & 0.25 & -0.13 \\
\hline Low-fat dairy products & 0.25 & \\
\hline Nuts & 0.16 & 0.15 \\
\hline Cold breakfast cereal and cereal bars & 0.15 & \\
\hline Bovine meat/beef (fatty cuts) & & 0.60 \\
\hline Processed meat & & 0.56 \\
\hline Bovine meat/beef (lean cuts) & 0.12 & 0.51 \\
\hline Vegetable oils & 0.21 & 0.48 \\
\hline Pastry and cakes & & 0.46 \\
\hline Mayonnaise and other dressings & & 0.44 \\
\hline Pizza and 'empanadas' & & 0.44 \\
\hline Snacks & & 0.43 \\
\hline Poultry & 0.17 & 0.42 \\
\hline Refined grains & & 0.41 \\
\hline Eggs & 0.21 & 0.36 \\
\hline Sweets and desserts & & 0.29 \\
\hline Sugar, jam, marmalade and 'Dulce de leche' & & 0.29 \\
\hline High-fat dairy products & 0.12 & 0.27 \\
\hline Organ meat & & 0.24 \\
\hline Animal fats and margarine & & 0.22 \\
\hline Pork and other meats & & 0.21 \\
\hline High-energy drinks & & $0 \cdot 19$ \\
\hline Coffee & & $0 \cdot 14$ \\
\hline Beer & & 0.13 \\
\hline Wine & & 0.11 \\
\hline Other alcoholic beverages & & 0.10 \\
\hline Proportion of total variance explained & $10 \cdot 3 \%$ & $7.4 \%$ \\
\hline
\end{tabular}

* Loadings $<0.10$ are not shown. 


\section{General characteristics and nutrient intake}

The eligible study population included 429 men and 542 women. Men in the highest quartile of the prudent diet were more educated $(10 \cdot 1 v .8 .7$ years), had higher prevalence overweight/obesity ( $85 v$. 72\%), a lower prevalence of current smoking (30 v. 42\%) and a non-significant trend to higher prevalence of hypertension ( $53 v .39 \%$ ) and older ages $(51.9 v$ v 55.2 years) compared with the lowest quartiles. Women, in the highest quartile of the prudent diet had higher prevalence overweight/obesity (75 v. 62\%) and a lower prevalence of current smoking (22 v. 38\%) compared with the lowest quartile.

Men in the highest quartile of the WL pattern were younger ( $51.4 v .54 .8$ years), more likely to smoke (40v. 30\%), with a lower prevalence of diabetes ( $8 v .15 \%)$ compared with the lowest quartile. Women in the highest quartile of the WL pattern were also younger ( $51.0 v$. 54.4 years), more likely to smoke (35 v. $21 \%$ ), with a lower prevalence of diabetes ( $5 v .11 \%)$ and overweight/obesity (64 v. 74\%) compared with the lowest quartile (Table 2)

In relation to nutrient intake, participants in the highest quartile of the prudent diet had lower intake of SFA, similar intake of unsaturated fats and higher intake of fibre and proteins compared with the lowest quartile. Participants in the highest quartile of the Western diet had a substantially higher intake of SFA, MUFA, PUFA and dietary cholesterol with a lower intake of fibre and carbohydrates compared with the lowest quartile. These differences resulted in a substantially higher energy intake in the highest quartile of the Western diet $v$. those in the highest quartile of the prudent diet (2805 $v$. $2167 \mathrm{kcal}(11736 v .699 \mathrm{~kJ})$ in women and $2903 v .2305 \mathrm{kcal}$ (12146v. 9644 kJ) in men). Participants in the two highest quartiles of the prudent and Western diets had lower intake of alcohol/2000 kcal (8368 kJ) compared with the lowest quartiles, except for women in the analysis of the prudent diet (Table 3).

\section{CVD risk factors}

Men in highest quartile of prudent diet had significantly lower apo B (mean adjusted difference $-8.5 \mathrm{mg} / 1 ; 95 \% \mathrm{CI}-15.8,-1.4$ ), total cholesterol $(-18.8 \mathrm{mg} / \mathrm{dl} ; 95 \%$ CI $-31.7,-5.9)$, LDL $(-16.5 \mathrm{mg} / \mathrm{dl} ; 95 \% \mathrm{CI}-27 \cdot 7,-5.3)$ and hs-CRP $(-1.6 \mathrm{mg} / \mathrm{l} ; 95 \%$ CI $-2 \cdot 3,-1 \cdot 0$ ) (Table 4) compared with men in the lowest quartile. Similar results were observed in women: those at highest quartile of prudent diet had lower apo B $(-6.6 \mathrm{mg} / \mathrm{l}$; $95 \%$ CI $-13 \cdot 0,-0 \cdot 3)$, total cholesterol $(-12 \cdot 0 \mathrm{mg} / \mathrm{dl} ; 95 \% \mathrm{CI}$ $-22.5,-5 \cdot 3)$ and LDL $(-9.3 \mathrm{mg} / \mathrm{dl} ; 95 \% \mathrm{CI}-18 \cdot 2,-0.5)$ (Table 5) compared with the lowest quartile. However, there was no association between prudent diet and hs-CRP in women. Prudent diet was not associated with plasma levels of HDL or apo A-I in either women or men.

In contrast, having a Western diet was not associated with a significant change in any of our outcomes in men or women, except for a non-significant trend ( $P$ value of trend 0.07-0.09) toward higher TAG, lower apo A-I and HDL in women.

In sensitivity analysis, when BMI was excluded from the models the results did not change, except for the association between prudent diet and apo $\mathrm{B}$ and hs-CRP, which lost statistical significance potentially indicating that BMI acted in this relationship more as a confounder than as a mediator. There was no significant interaction between BMI and age.

Table 2. General characteristics of the study population according to quartiles (Q) of dietary pattern scores

\begin{tabular}{|c|c|c|c|c|c|c|c|c|c|c|}
\hline & \multicolumn{5}{|c|}{ Prudent diet } & \multicolumn{5}{|c|}{ Western-like diet } \\
\hline & Q1 & Q2 & Q3 & Q4 & $P^{*}$ & Q1 & Q2 & Q3 & Q4 & $P^{*}$ \\
\hline \multicolumn{11}{|l|}{ Men (n 429) } \\
\hline Age† (years) & $51 \cdot 9$ & 53.4 & $52 \cdot 6$ & $55 \cdot 2$ & 0.057 & $54 \cdot 8$ & $54 \cdot 7$ & $51 \cdot 8$ & $51 \cdot 4$ & 0.004 \\
\hline Educational level† (years) & $8 \cdot 7$ & $10 \cdot 3$ & $10 \cdot 7$ & $10 \cdot 1$ & 0.004 & $10 \cdot 0$ & $10 \cdot 3$ & $10 \cdot 0$ & $9 \cdot 8$ & 0.715 \\
\hline Physical inactivity (\%) & 44 & 57 & 58 & 49 & 0.154 & 51 & 53 & 54 & 50 & 0.923 \\
\hline Current smokers (\%) & 42 & 41 & 28 & 30 & 0.025 & 30 & 29 & 42 & 40 & 0.041 \\
\hline Alcohol use (\%) & 66 & 50 & 58 & 61 & 0.150 & 56 & 66 & 51 & 62 & 0.130 \\
\hline Overweight/obese (\%) & 72 & 78 & 78 & 85 & 0.019 & 85 & 74 & 74 & 80 & 0.411 \\
\hline Diabetes (\%) & 10 & 8 & 7 & 14 & 0.459 & 15 & 12 & 6 & 8 & 0.022 \\
\hline Hypertension (\%) & 39 & 40 & 41 & 53 & 0.052 & 44 & 46 & 38 & 46 & 0.597 \\
\hline \multicolumn{11}{|l|}{ Women (n 542) } \\
\hline Age† (years) & $52 \cdot 6$ & $51 \cdot 1$ & $52 \cdot 6$ & $53 \cdot 5$ & 0.333 & 54.4 & $52 \cdot 5$ & $51 \cdot 8$ & $51 \cdot 0$ & 0.008 \\
\hline Educational level† (years) & 9.5 & $10 \cdot 1$ & 9.7 & $10 \cdot 1$ & 0.434 & $9 \cdot 6$ & 9.9 & $10 \cdot 0$ & 9.5 & 0.905 \\
\hline Physical inactivity (\%) & 70 & 65 & 69 & 70 & 0.764 & 68 & 71 & 69 & 67 & 0.874 \\
\hline Current smokers (\%) & 38 & 29 & 23 & 22 & 0.000 & 21 & 26 & 29 & 35 & 0.009 \\
\hline Alcohol use (\%) & 27 & 35 & 34 & 37 & 0.145 & 32 & 37 & 30 & 33 & 0.761 \\
\hline Overweight/obese (\%) & 62 & 74 & 70 & 75 & 0.037 & 74 & 76 & 68 & 64 & 0.041 \\
\hline Diabetes (\%) & 7 & 8 & 9 & 7 & 0.877 & 11 & 9 & 5 & 5 & 0.026 \\
\hline Hypertension (\%) & 38 & 36 & 45 & 36 & 0.384 & 38 & 47 & 35 & 34 & 0.185 \\
\hline
\end{tabular}

* $P$-value for linear trend for continuous variables and $x^{2}$ for categorical variables.

$\dagger$ Mean values. Alcohol intake includes moderate and heavy drinkers. Moderate drinker was defined as $\leq 14$ drinks in men or $\leq 7$ drinks in women per week. Heavy drinker was defined as $\geq 15$ drinks/week in men and $\geq 8$ drinks/week in women. Physical inactivity was defined as energy expenditure $<600 \mathrm{MET}$-min/week. Diabetes: fasting glucose $\geq 126 \mathrm{mg} / \mathrm{dl}$ or selfreported history of diabetes. Current smokers are those who are currently smoking or quit smoking for $<12$ months. Educational level was defined by years of schooling. BMI was calculated by dividing weight in kilograms by height in metres squared $\left(\mathrm{kg} / \mathrm{m}^{2}\right)$, participants were categorised into normal weight $\left(18.5-24.9 \mathrm{~kg} / \mathrm{m}^{2}\right)$, overweight $\left(25.0-29.9 \mathrm{~kg} / \mathrm{m}^{2}\right)$ and obese $\left(\geq 30.0 \mathrm{~kg} / \mathrm{m}^{2}\right)$. Hypertension: systolic blood pressure $\geq 140 \mathrm{mmHg}$ and/or diastolic blood pressure $\geq 90 \mathrm{mmHg}$ and/or use of antihypertensive medication. 
Table 3. Nutrient intakes according to quartiles $(Q)$ of dietary pattern scores

\begin{tabular}{|c|c|c|c|c|c|c|c|c|c|c|}
\hline & \multicolumn{5}{|c|}{ Prudent diet } & \multicolumn{5}{|c|}{ Western-like diet } \\
\hline & Q1 & Q2 & Q3 & Q4 & $P^{*}$ & Q1 & Q2 & Q3 & Q4 & $P^{*}$ \\
\hline \multicolumn{11}{|l|}{ Men $(n$ 429) } \\
\hline Protein (\% energy) & $14 \cdot 1$ & $15 \cdot 1$ & $15 \cdot 7$ & $15 \cdot 8$ & 0.001 & $14 \cdot 2$ & $15 \cdot 2$ & $15 \cdot 0$ & $16 \cdot 2$ & 0.001 \\
\hline Carbohydrate (\% energy) & $52 \cdot 4$ & $52 \cdot 1$ & 51.9 & 53.4 & 0.563 & $56 \cdot 1$ & $51 \cdot 4$ & 53.5 & 48.5 & 0.000 \\
\hline Fibre (g/2000 kcal (8368 kJ)) & 11.4 & 13.5 & $16 \cdot 7$ & 19.9 & 0.000 & $18 \cdot 5$ & $15 \cdot 9$ & 14.6 & $12 \cdot 3$ & 0.000 \\
\hline Total fat (\% energy) & $28 \cdot 2$ & 28.9 & 28.9 & $26 \cdot 9$ & 0.294 & $24 \cdot 4$ & 28.4 & $28 \cdot 0$ & $32 \cdot 0$ & 0.000 \\
\hline SFA (\% energy) & 9.9 & $10 \cdot 1$ & $9 \cdot 7$ & $8 \cdot 7$ & 0.005 & $7 \cdot 8$ & $9 \cdot 6$ & 9.7 & $11 \cdot 3$ & 0.000 \\
\hline MUFA (\% energy) & $10 \cdot 3$ & $10 \cdot 3$ & $10 \cdot 3$ & 9.5 & 0.113 & $8 \cdot 6$ & $10 \cdot 2$ & 9.9 & $11 \cdot 6$ & 0.000 \\
\hline PUFA (\% energy) & $5 \cdot 3$ & 5.4 & $5 \cdot 6$ & $5 \cdot 0$ & 0.408 & 4.4 & $5 \cdot 2$ & 5.5 & $6 \cdot 1$ & 0.000 \\
\hline Cholesterol (mg/2000 kcal (8368 kJ)) & $220 \cdot 2$ & $231 \cdot 3$ & 234.8 & 213.5 & 0.413 & $181 \cdot 4$ & 227.8 & $232 \cdot 4$ & 258.6 & 0.000 \\
\hline Alcohol (g/2000 kcal (8368 kJ)) & 5.9 & 3.4 & 3.0 & $2 \cdot 7$ & 0.006 & 7.4 & $4 \cdot 2$ & $1 \cdot 8$ & 1.4 & 0.000 \\
\hline Total energy intake & 1592 & 1950 & 1983 & 2305 & 0.000 & 1138 & 1617 & 2177 & 2903 & 0.000 \\
\hline \multicolumn{11}{|l|}{ Women ( $n$ 542) } \\
\hline Protein (\% energy) & $14 \cdot 3$ & $15 \cdot 3$ & $15 \cdot 2$ & $16 \cdot 0$ & 0.001 & 14.5 & $15 \cdot 5$ & $16 \cdot 0$ & $14 \cdot 8$ & 0.333 \\
\hline Carbohydrate (\% energy) & $55 \cdot 7$ & $52 \cdot 2$ & $55 \cdot 1$ & $53 \cdot 6$ & 0.431 & $57 \cdot 2$ & $54 \cdot 3$ & $51 \cdot 6$ & $53 \cdot 6$ & 0.001 \\
\hline Fibre (g/2000 kcal (8368 kJ)) & $12 \cdot 2$ & $15 \cdot 8$ & $18 \cdot 1$ & $23 \cdot 4$ & 0.000 & $21 \cdot 4$ & $18 \cdot 5$ & $15 \cdot 9$ & $13 \cdot 6$ & 0.000 \\
\hline Total fat (\% energy) & $27 \cdot 8$ & 29.8 & $27 \cdot 1$ & $27 \cdot 9$ & 0.443 & $25 \cdot 4$ & $27 \cdot 3$ & $30 \cdot 3$ & $29 \cdot 6$ & 0.000 \\
\hline SFA (\% energy) & 9.9 & $9 \cdot 8$ & $9 \cdot 2$ & 8.7 & 0.001 & $8 \cdot 0$ & $9 \cdot 1$ & $10 \cdot 2$ & $10 \cdot 4$ & 0.000 \\
\hline MUFA (\% energy) & $9 \cdot 6$ & $10 \cdot 2$ & $9 \cdot 3$ & $9 \cdot 3$ & $0 \cdot 156$ & 8.5 & $9 \cdot 3$ & $10 \cdot 4$ & $10 \cdot 3$ & 0.000 \\
\hline PUFA (\% energy) & $5 \cdot 3$ & $6 \cdot 0$ & 4.9 & $5 \cdot 3$ & 0.267 & 4.9 & $5 \cdot 0$ & 5.9 & $5 \cdot 7$ & 0.000 \\
\hline Cholesterol (mg/2000 kcal (8368 kJ)) & $220 \cdot 9$ & $227 \cdot 7$ & 219.5 & 211.5 & 0.380 & 193.1 & 217 & 239.6 & $229 \cdot 8$ & 0.002 \\
\hline Alcohol $(\mathrm{g} / 2000 \mathrm{kcal}(8368 \mathrm{~kJ}))$ & $1 \cdot 2$ & 1.7 & 1.5 & 0.9 & 0.345 & $2 \cdot 3$ & $2 \cdot 0$ & 0.7 & 0.35 & 0.000 \\
\hline Total energy intake & 1699 & 1725 & 1960 & 2167 & 0.000 & 1148 & 1576 & 2024 & 2805 & 0.000 \\
\hline
\end{tabular}

* $P$-value for linear trend for continuous variables and $x^{2}$ for categorical variables.

Table 4. Mean biomarkers values by quartiles $(Q)$ of dietary pattern scores in men

\begin{tabular}{|c|c|c|c|c|c|c|c|c|c|c|}
\hline & \multicolumn{5}{|c|}{ Prudent diet } & \multicolumn{5}{|c|}{ Western-like diet } \\
\hline & Q1 & Q2 & Q3 & Q4 & $P^{\star}$ & Q1 & Q2 & Q3 & Q4 & $P^{*}$ \\
\hline \multicolumn{11}{|l|}{ Apo B } \\
\hline Mean (mg/l) & $90 \cdot 9$ & $86 \cdot 9$ & $87 \cdot 8$ & 84.3 & & 88.4 & $88 \cdot 6$ & 85.4 & $89 \cdot 1$ & \\
\hline Adjusted mean difference & Ref. & $-2 \cdot 2$ & $-3 \cdot 7$ & -8.5 & 0.018 & Ref. & 1.0 & $-1 \cdot 7$ & 1.5 & 0.907 \\
\hline \multicolumn{11}{|l|}{ Apo A-I } \\
\hline Mean (mg/l) & 111.4 & $106 \cdot 7$ & $109 \cdot 9$ & $109 \cdot 0$ & & 111.0 & $110 \cdot 5$ & $106 \cdot 4$ & $110 \cdot 1$ & \\
\hline Adjusted mean difference & Ref. & $-2 \cdot 7$ & 0.0 & $-2 \cdot 7$ & 0.212 & Ref. & -3.8 & -0.7 & $-3 \cdot 1$ & 0.356 \\
\hline \multicolumn{11}{|l|}{ Total cholesterolf } \\
\hline Mean $(\mathrm{mg} / \mathrm{dl})$ & 209.4 & $206 \cdot 4$ & $205 \cdot 8$ & 193.9 & & $202 \cdot 7$ & $206 \cdot 1$ & $201 \cdot 8$ & 204.9 & \\
\hline Adjusted mean difference & Ref. & -3.0 & $-5 \cdot 1$ & $-18 \cdot 8$ & 0.009 & Ref. & 3.0 & -0.7 & $2 \cdot 1$ & 0.959 \\
\hline \multicolumn{11}{|l|}{ LDL†‡ } \\
\hline Mean $(\mathrm{mg} / \mathrm{dl})$ & 137.9 & $128 \cdot 3$ & $130 \cdot 7$ & $120 \cdot 0$ & & 129.7 & 130.5 & $126 \cdot 5$ & 134.3 & \\
\hline Adjusted mean difference & Ref. & $-3 \cdot 7$ & $-6 \cdot 2$ & $-16 \cdot 5$ & 0.007 & Ref. & 2.9 & 0.9 & 9.7 & 0.290 \\
\hline \multicolumn{11}{|l|}{$\mathrm{HDL}$} \\
\hline Mean (mg/dl) & $42 \cdot 7$ & $40 \cdot 7$ & 41.4 & 39.4 & & $42 \cdot 1$ & 42.5 & $39 \cdot 6$ & 41.3 & \\
\hline Adjusted mean difference & Ref. & -0.7 & 0.2 & $-2 \cdot 2$ & 0.244 & Ref. & -0.45 & $-3 \cdot 6$ & $-2 \cdot 1$ & 0.266 \\
\hline \multicolumn{11}{|l|}{ TAG } \\
\hline Mean (mg/dl) & $158 \cdot 0$ & $176 \cdot 8$ & 204.6 & $177 \cdot 2$ & & $175 \cdot 1$ & $189 \cdot 6$ & $170 \cdot 4$ & $182 \cdot 2$ & \\
\hline Adjusted mean difference & Ref. & $19 \cdot 3$ & 38.4 & 11.3 & 0.553 & Ref. & $25 \cdot 6$ & 8.9 & 18.8 & 0.353 \\
\hline \multicolumn{11}{|l|}{ Hs-CRP $\ddagger$} \\
\hline Mean (mg/l) & 3.8 & 3.9 & $3 \cdot 3$ & 3.7 & & $2 \cdot 9$ & 3.1 & 3.9 & 4.9 & \\
\hline Adjusted mean difference & Ref. & $-1 \cdot 0$ & $-1 \cdot 3$ & -1.6 & 0.018 & Ref. & 0.07 & 0.63 & 1.39 & 0.311 \\
\hline
\end{tabular}

Ref., referent values; Hs-CRP, high-sensitivity C-reactive protein.

* Linear trends tests were conducted to assess the associations with multivariable regression analysis by assigning the median of the observations in each quartile and computing the $P$-value for each trend. Multivariable model adjusted for: age, BMl, education, energy intake, physical activity, diabetes and smoking status.

$\dagger$ Calculated for participants who fasted $>9 \mathrm{~h}$ and TAG concentrations $\leq 400 \mathrm{mg} / \mathrm{dl}$ according to Friedwald's equation. Alcohol consumption was not considered as covariate because it was included into the dietary patterns.

¥ Total cholesterol, LDL and Hs-CRP were log-transformed before running the ordinary linear regression models. The log-transformed means were then converted back to their usual scale.

\section{Discussion}

We found that a prudent diet, that is high in fruit and vegetables, seafood, whole grains and low-fat dairy products, was associated with lower apo B, total cholesterol and LDL-cholesterol in both sexes and with lower hs-CRP in men. In contrast, a Western diet was not significantly associated with any of the selected serum lipid or inflammatory biomarkers. Our result for the prudent diet could be partially explained by higher dietary fibre intake ${ }^{(35,36)}$ and proteins (mainly from fish and vegetables) and the reduction 
Dietary patterns and risk factors

Table 5. Mean biomarkers values by quartiles $(\mathrm{Q})$ of dietary pattern scores in women

\begin{tabular}{|c|c|c|c|c|c|c|c|c|c|c|}
\hline & \multicolumn{5}{|c|}{ Prudent diet } & \multicolumn{5}{|c|}{ Western-like diet } \\
\hline & Q1 & Q2 & Q3 & Q4 & $P^{*}$ & Q1 & Q2 & Q3 & Q4 & $P^{*}$ \\
\hline \multicolumn{11}{|l|}{ Apo B } \\
\hline Mean (mg/l) & 89.1 & 84.2 & 83.1 & $85 \cdot 2$ & & $84 \cdot 2$ & 87.5 & 83.5 & $86 \cdot 3$ & \\
\hline Adjusted mean difference & Ref. & $-5 \cdot 7$ & $-6 \cdot 8$ & $-6 \cdot 6$ & 0.043 & Ref. & 4.5 & 0.7 & $5 \cdot 7$ & 0.372 \\
\hline \multicolumn{11}{|l|}{ Apo A-I } \\
\hline Mean $(\mathrm{mg} / \mathrm{l})$ & $125 \cdot 9$ & $122 \cdot 7$ & $125 \cdot 5$ & $124 \cdot 1$ & & $125 \cdot 1$ & $124 \cdot 3$ & 124.9 & 123.6 & \\
\hline Adjusted mean difference & Ref. & $-3 \cdot 0$ & -0.1 & $-2 \cdot 7$ & 0.597 & Ref. & -2.6 & -3.4 & $-7 \cdot 0$ & 0.095 \\
\hline \multicolumn{11}{|l|}{ Total cholesterolł } \\
\hline Mean $(\mathrm{mg} / \mathrm{dl})$ & 217.6 & $205 \cdot 1$ & 204.6 & 208.9 & & $207 \cdot 0$ & 212.5 & $205 \cdot 8$ & $210 \cdot 9$ & \\
\hline Adjusted mean difference & Ref. & $-12 \cdot 1$ & -14.4 & $-12 \cdot 0$ & 0.018 & Ref. & 7.9 & $1 \cdot 2$ & $9 \cdot 2$ & 0.476 \\
\hline \multicolumn{11}{|l|}{ LDL† } \\
\hline Mean $(\mathrm{mg} / \mathrm{dl})$ & 138.6 & 138.6 & 129.7 & $131 \cdot 2$ & & $131 \cdot 1$ & 134.6 & 128.8 & $135 \cdot 1$ & \\
\hline Adjusted mean difference & Ref. & $-8 \cdot 2$ & -9.6 & $-9 \cdot 3$ & 0.027 & Ref. & 0.2 & -0.0 & 0.3 & 0.488 \\
\hline \multicolumn{11}{|l|}{ HDL } \\
\hline Mean $(\mathrm{mg} / \mathrm{dl})$ & 50.6 & 47.5 & $50 \cdot 8$ & $51 \cdot 1$ & & $50 \cdot 6$ & $49 \cdot 6$ & $49 \cdot 6$ & 50.5 & \\
\hline Adjusted mean difference & Ref. & $-2 \cdot 6$ & 0.5 & 0.1 & 0.419 & Ref. & $-2 \cdot 1$ & -3.1 & $-4 \cdot 1$ & 0.093 \\
\hline \multicolumn{11}{|l|}{ TAG } \\
\hline Mean (mg/dl) & $144 \cdot 2$ & 134.1 & $122 \cdot 4$ & 134.0 & & $128 \cdot 9$ & $140 \cdot 2$ & 138.3 & $127 \cdot 4$ & \\
\hline Adjusted mean difference & Ref. & $-14 \cdot 2$ & -23.9 & -17.5 & 0.063 & Ref. & $19 \cdot 2$ & $26 \cdot 1$ & $27 \cdot 4$ & 0.075 \\
\hline \multicolumn{11}{|l|}{ Hs-CRP } \\
\hline Mean (mg/l) & 3.9 & 4.0 & 3.6 & 3.4 & & 3.7 & 3.7 & 4.2 & $3 \cdot 2$ & \\
\hline Adjusted mean difference & Ref. & -0.2 & -0.5 & -0.8 & 0.263 & Ref. & 0.2 & 0.8 & 0.4 & 0.472 \\
\hline
\end{tabular}

Ref., referent values; Hs-CRP, high-sensitivity C-reactive protein.

* Linear trends tests were conducted to assess the associations with multivariable regression analysis by assigning the median of the observations in each quartile and computing the $P$-value for each trend. Multivariable model adjusted for: age, BMI, education, energy intake, physical activity, diabetes and smoking status.

† Calculated for participants who fasted $>9 \mathrm{~h}$ and TAG concentrations $\leq 400 \mathrm{mg} / \mathrm{dl}$ according to Friedwald's equation. Alcohol consumption was not considered as covariate because it was included into the dietary patterns.

¥ Total cholesterol, LDL and Hs-CRP were log-transformed before running the ordinary linear regression models. The log-transformed means were then converted back to their usual scale.

on SFA in those at the highest quartile compared with lowest quartile and by lack of any substantial difference in carbohydrates across these quartiles ${ }^{(37)}$. Lack of association between the Western diet and the lipid profiles may be due to the combination of nutrients with opposite effects on plasmatic lipoproteins. The increase in LDL-cholesterol as consequence of higher intake of SFA and dietary cholesterol ${ }^{(38)}$ may have been neutralised by the effect of higher intake of unsaturated fats, proteins with high load of lean cuts of red meat and poultry ${ }^{(39)}$, which have demonstrated to reduce VLDL- and LDL- and total cholesterol, apo ${ }^{(40)}$.

On the basis of differences in composition of dietary fat alone, we expected to observe a higher HDL-cholesterol ${ }^{(37)}$ among those at the highest quartile of Western diet, which our data did not show. Other determinants of HDL including physical activity and alcohol use were similar across quartiles of Western diet.

A number of previous studies have examined the relationship between dietary patterns and biomarkers of inflammation and dyslipidemia using principle components analysis ${ }^{(27,32-34,41)}$, however this was the first study to report the reduction of total cholesterol, LDL and apo B with a prudent diet in both sexes. Similar to ours, most previous studies did not find a significant association between prudent diet and apo A-I and HDL-cholesterol ${ }^{(17,18,23,25,29,30)}$.

The results of previous studies on the association between Western diets and lipid and inflammatory profiles are mixed with several studies showing an association with higher LDL- and total cholesterol ${ }^{(27,28,41-43)}$ and others reporting no associations with these lipoproteins ${ }^{(32-34)}$. All of these studies were from high-income countries. The only previous study from a middle-income country was from Brazil and showed that a 'processed food' pattern was associated with higher LDL-, HDL- and total cholesterol ${ }^{(41)}$

Our analysis had several strengths. We chose principal component analysis to derive dietary patterns because they can assess the relationship between overall diet, examining the impact of interactions between different nutrients or foods, usually providing associations with greater consistency and strength than they have been possible using analyses of single nutrients or foods. In addition, some important epidemiological studies found significant association among diet, cardiovascular risk factors and cardiovascular events with this approach ${ }^{(25,27,41)}$. Data on food intake were obtained through a validated $F_{F Q}{ }^{(19)}$.

However, our study had several limitations as well. The reported associations between dietary patterns and CVD risk factors in our cross-sectional study may not be due to causal relationships but rather due to unmeasured confounding and potential reverse causation as high-risk lipid profiles may have encouraged participants to change their diet. However, the potential for reverse causation bias is fairly small in this population as none of the participants were under lipidlowering treatment and most participants had not checked their serum lipid profile before enrolling in this study. In addition, the reverse causality bias would lead to a positive association between plasma lipids and higher score of prudent diet; however, we observed a negative association. Measurement errors in reporting diet using the FFQ could affect our results by introducing random variation and lowering the significance of 
the associations. Because dietary patterns may differ by sex, race, local culture and geographical region, our results may not be generalisable to other populations. Finally, the proportion of variance explained by the two major dietary patterns was $<20 \%$ of total variance, suggesting the potential existence of other patterns that were not identified in the present analysis. However, similar results were reported in several previous studies $^{(28,34,41)}$

Our findings can have important public health implication for CVD prevention in South America. We found that a prudent diet with high intake of fruits and vegetables, seafood, whole grain and low-fat dairy products is associated with a healthier lipid profile that in itself is associated with lower cardiovascular risk $^{(44)}$. In contrast, a Western diet with higher intake of both lean and fatty red meat did not affect the lipid profile substantially. The effect of red meat consumption on CVD is still a topic of debate. Some studies have reported an increased risk of ischaemic stroke ${ }^{(45-47)}$, diabetes ${ }^{(48-50)}$ and mortality ${ }^{(51,52)}$ with higher intake of red meat, whereas others found no effect $^{(49,53,54)}$. Our results may point to new avenues of enquiry in this regard. Our findings also indicate that future public health campaigns and programmes in Argentina and the Southern Cone should promote higher intake of fruits and vegetables, seafood and whole grains to reduce the burden of CVD. Follow-up of this cohort study will allow the prospective investigation of the effect of dietary patterns on various CVD and other chronic disease outcomes.

\section{Acknowledgements}

We are grateful to CESCAS I study participants, without whom this research would not be possible. We also want to thank Daniela Defago, for her support for the completion of the food composition database.

This work was supported by the National Heart, Lung, and Blood Institute of the National Institutes of Health under contract no. 268200900029C, and by Fogarty International Center, grant no. 1R25TW009340-01.

All authors significantly contributed in the manuscript: R. P. conceived the study aims and design. A. R., V. I. contributed to interpretation of results. R. P., L. G. and N. E. performed the analysis and interpreted the results. R. P., V. E., N. E. and A. R. contributed to the interpretation of results. R. P. drafted the manuscript. A. R. revised the manuscript. R. P. is guarantor.

The authors declare that there are no conflicts of interest to declare.

\section{References}

1. GBD DALYs and HALE Collaborators, Murray CJ, Barber RM, et al. (2015) Global, regional, and national disability-adjusted life years (DALYs) for 306 diseases and injuries and healthy life expectancy (HALE) for 188 countries, 1990-2013: quantifying the epidemiological transition. Lancet 386, 2145-2191.

2. Lopez AD, Mathers CD, Ezzati M, et al. (2006) Global and regional burden of disease and risk factors, 2001: systematic analysis of population health data. Lancet 367, 1747-1757.
3. Global Burden of Disease (2015) Systematic analysis for the Global Burden of Disease Study. http://vizhub.healthdata.org/ gbd-compare/arrow (accessed January 2017).

4. Rubinstein AL, Irazola VE, Calandrelli M, et al. (2015) Multiple cardiometabolic risk factors in the Southern Cone of Latin America: a population-based study in Argentina, Chile, and Uruguay. Int J Cardiol 183, 82-88.

5. Durán P (2005) Transición epidemiológica nutricional o el 'efecto mariposa' (Nutritional epidemiological transition or 'butterfly effect'). Archivos Argentinos de pediatría 103, 195-197.

6. Micha R, Khatibzadeh S, Shi P, et al. (2015) Global, regional and national consumption of major food groups in 1990 and 2010: a systematic analysis including 266 country-specific nutrition surveys worldwide. BMJ Open 5, 1-23.

7. Barria RM \& Amigo H (2006) [Nutrition transition: a review of Latin American profile]. Arch Latinoam Nutr 56, 3-11.

8. Latin America and the Caribbean Food and Agriculture (2014) FAO Statistical Yearbook. http://www.fao.org/docrep/019/ i3592e/i3592e.pdf (accessed January 2016).

9. Bermudez OI \& Tucker KL (2003) Trends in dietary patterns of Latin American populations. Cad Saude Publica 19, Suppl. 1, S87-S99.

10. Hu FB (2002) Dietary pattern analysis: a new direction in nutritional epidemiology. Curr Opin Lipidol 13, 3-9.

11. Jacques PF \& Tucker KL (2001) Are dietary patterns useful for understanding the role of diet in chronic disease? Am J Clin Nutr 73, 1-2.

12. Brunner EJ, Mosdol A, Witte DR, et al. (2008) Dietary patterns and 15-y risks of major coronary events, diabetes, and mortality. Am J Clin Nutr 87, 1414-1421.

13. Hoffmann K, Zyriax BC, Boeing H, et al. (2004) A dietary pattern derived to explain biomarker variation is strongly associated with the risk of coronary artery disease. Am J Clin Nutr 80, 633-640.

14. Barbaresko J, Koch M, Schulze MB, et al. (2013) Dietary pattern analysis and biomarkers of low-grade inflammation: a systematic literature review. Nutr Rev 71, 511-527.

15. Rubinstein AL, Irazola VE, Poggio R, et al. (2011) Detection and follow-up of cardiovascular disease and risk factors in the Southern Cone of Latin America: the CESCAS I study. BMJ Open 1, 1-6.

16. Sorlie PD, Aviles-Santa LM, Wassertheil-Smoller S, et al. (2010) Design and implementation of the Hispanic Community Health Study/Study of Latinos. Ann Epidemiol 20, 629-641.

17. Global Adult Tobacco Survey (2010). GATS questionnaire. http://www.tobaccofreecenter.org (accessed September 2016).

18. Sniderman AD \& Kiss RS (2007) The strengths and limitations of the apoB/apoA-I ratio to predict the risk of vascular disease: a Hegelian analysis. Curr Atheroscler Rep 9, 261-265.

19. Elorriaga N, Irazola VE, Defagó MD, et al. (2015) Validation of a self-administered FFQ in adults in Argentina, Chile and Uruguay. Public Health Nutr 18, 59-67.

20. Universidad Nacional de Luján (2010) Tabla de Composición de Alimentos (Food Composition Table). www.unlu.edu.ar/ argenfood/Tablas/Tabla.htm (accessed September 2016).

21. Food and Agriculture Organization (2010) Tabla de composición de alimentos de América Latina (Latin American Food Composition Table). http://www.rlc.fao.org/es/conozca-fao/que-hace-fao/ estadisticas/composicion-alimentos (accessed September 2015).

22. Ministerio de Salud (2013) SARA: Sistema de Análisis y Registro de Alimentos (SARA: System Analysis and Food Registry). http:// datos.dinami.gov.ar/produccion/sara/ (accessed September 2015).

23. US Department of Agriculture, Agricultural Research Service (2008) USDA National Nutrient Database for standard reference, release 21. http://www.ars.usda.gov/ba/bhnrc/ndl (accessed January 2016). 
24. Dati F, Tate JR, Marcovina SM, et al. (2004) First WHO/IFCC international reference reagent for lipoprotein(a) for immunoassay - Lp(a) SRM 2B. Clin Chem Lab Med 42, 670-676.

25. Hu FB, Rimm EB, Stampfer MJ, et al. (2000) Prospective study of major dietary patterns and risk of coronary heart disease in men. Am J Clin Nutr 72, 912-921.

26. Fung TT, Rimm EB, Spiegelman D, et al. (2001) Association between dietary patterns and plasma biomarkers of obesity and cardiovascular disease risk. Am J Clin Nutr 73, 61-67.

27. Mikkila V, Rasanen L, Raitakari OT, et al. (2007) Major dietary patterns and cardiovascular risk factors from childhood to adulthood. The Cardiovascular Risk in Young Finns Study. Br J Nutr 98, 218-225.

28. Sadakane A, Tsutsumi A, Gotoh T, et al. (2008) Dietary patterns and levels of blood pressure and serum lipids in a Japanese population. J Epidemiol 18, 58-67.

29. Martinez ME, Marshall JR \& Sechrest L (1998) Invited commentary: factor analysis and the search for objectivity. $\mathrm{Am}$ J Epidemiol 148, 17-19.

30. Newby PK \& Tucker KL (2004) Empirically derived eating patterns using factor or cluster analysis: a review. Nutr Rev 62 , $177-203$.

31. Willet W (2013) Nutritional Epidemiology, 3rd ed. Oxford: Oxford University Press.

32. Bouchard-Mercier A, Paradis AM, Godin G, et al. (2010) Associations between dietary patterns and LDL peak particle diameter: a cross-sectional study. J Am Coll Nutr 29, 630-637.

33. Labonte ME, Dewailly E, Lucas M, et al. (2014) Traditional dietary pattern is associated with elevated cholesterol among the Inuit of Nunavik. J Acad Nutr Diet 123, 1-4.

34. Kerver JM, Yang EJ, Bianchi L, et al. (2003) Dietary patterns associated with risk factors for cardiovascular disease in healthy US adults. Am J Clin Nutr 78, 1103-1110.

35. Queenan KM, Stewart ML, Smith KN, et al. (2007) Concentrated oat beta-glucan, a fermentable fiber, lowers serum cholesterol in hypercholesterolemic adults in a randomized controlled trial. Nutr $J \mathbf{6}, 6$.

36. Tighe P, Duthie G, Vaughan N, et al. (2010) Effect of increased consumption of whole-grain foods on blood pressure and other cardiovascular risk markers in healthy middle-aged persons: a randomized controlled trial. Am J Clin Nutr 92, 733-740.

37. Micha R \& Mozaffarian D (2010) Saturated fat and cardiometabolic risk factors, coronary heart disease, stroke, and diabetes: a fresh look at the evidence. Lipids 45, 893-905.

38. Berger S, Raman G, Vishwanathan R, et al. (2015) Dietary cholesterol and cardiovascular disease: a systematic review and meta-analysis. Am J Clin Nutr 102, 276-294.

39. Maki KC, Van Elswyk ME, Alexander DD, et al. (2012) A metaanalysis of randomized controlled trials that compare the lipid effects of beef versus poultry and/or fish consumption. J Clin Lipidol 6, 352-361.
40. Beauchesne-Rondeau E, Gascon A, Bergeron J, et al. (2003) Plasma lipids and lipoproteins in hypercholesterolemic men fed a lipid-lowering diet containing lean beef, lean fish, or poultry. Am J Clin Nutr 77, 587-593.

41. Olinto MT, Gigante DP, Horta B, et al. (2012) Major dietary patterns and cardiovascular risk factors among young Brazilian adults. Eur J Nutr 51, 281-291.

42. Eilat-Adar S, Mete M, Fretts A, et al. (2013) Dietary patterns and their association with cardiovascular risk factors in a population undergoing lifestyle changes: The Strong Heart Study. Nutr Metab Cardiovasc Dis 23, 528-535.

43. Van Dam RM, Grievink L, Ocke MC, et al. (2003) Patterns of food consumption and risk factors for cardiovascular disease in the general Dutch population. Am J Clin Nutr 77, 1156-1163.

44. Emerging Risk Factors Collaboration, Di Angelantonio E, Sarwar N, et al. (2009) Major lipids, apolipoproteins, and risk of vascular disease. JAMA 302, 1993-2000.

45. Bernstein AM, Pan A, Rexrode KM, et al. (2012) Dietary protein sources and the risk of stroke in men and women. Stroke 43, 637-644.

46. Kaluza J, Wolk A \& Larsson SC (2012) Red meat consumption and risk of stroke: a meta-analysis of prospective studies. Stroke 43, 2556-2560.

47. Chen GC, Lv DB, Pang Z, et al. (2013) Red and processed meat consumption and risk of stroke: a meta-analysis of prospective cohort studies. Eur J Clin Nutr 67, 91-95.

48. Pan A, Sun Q, Bernstein AM, et al. (2013) Changes in red meat consumption and subsequent risk of type 2 diabetes mellitus: three cohorts of US men and women. JAMA Intern Med 173, $1328-1335$.

49. Micha R, Michas G \& Mozaffarian D (2012) Unprocessed red and processed meats and risk of coronary artery disease and type 2 diabetes - an updated review of the evidence. Curr Atheroscler Rep 14, 515-524.

50. Pan A, Sun Q, Bernstein AM, et al. (2011) Red meat consumption and risk of type 2 diabetes: 3 cohorts of US adults and an updated meta-analysis. Am J Clin Nutr 94, 1088-1096.

51. Pan A, Sun Q, Bernstein AM, et al. (2012) Red meat consumption and mortality: results from 2 prospective cohort studies. Arch Intern Med 172, 555-563.

52. Bernstein AM, Sun Q, Hu FB, et al. (2010) Major dietary protein sources and risk of coronary heart disease in women. Circulation 122, 876-883.

53. Rohrmann S, Overvad K, Bueno-de-Mesquita HB, et al. (2013) Meat consumption and mortality - results from the European Prospective Investigation into Cancer and Nutrition. BMC Med 11, 63.

54. Micha R, Wallace SK \& Mozaffarian D (2010) Red and processed meat consumption and risk of incident coronary heart disease, stroke, and diabetes mellitus: a systematic review and meta-analysis. Circulation 121, 2271-2283. 